\title{
Like and share: associations between social media engagement and dietary choices in children
}

\author{
Heather J Baldwin ${ }^{1,2}$, Becky Freeman ${ }^{1,3, *}$ and Bridget Kelly ${ }^{4}$ \\ ${ }^{1}$ Prevention Research Collaboration, Sydney School of Public Health, University of Sydney, Sydney, NSW 2006, \\ Australia: ${ }^{2}$ Biostatistics Training Programme, New South Wales Ministry of Health, North Sydney, NSW, Australia: \\ ${ }^{3}$ Charles Perkins Centre, University of Sydney, Sydney, NSW, Australia: ${ }^{4}$ Early Start, School of Health \& Society, \\ University of Wollongong, Wollongong, NSW, Australia
}

Submitted 20 October 2017: Final revision received 10 June 2018: Accepted 26 June 2018: First published online 08 August 2018

\begin{abstract}
Objective: To examine whether social media and online behaviours are associated with unhealthy food and beverage consumption in children.

Design: A cross-sectional online survey was used to assess Internet and social media use, including engagement with food and beverage brand content, and frequency of consumption of unhealthy foods and beverages. Linear regression models were used to examine associations between online behaviours, including engagement with food and beverage brand content, and consumption of unhealthy foods and beverages, adjusting for age, sex and socio-economic status. Setting: New South Wales, Australia, in 2014.

Subjects: Children aged 10-16 years ( $n$ 417).

Results: Watching food brand video content on YouTube, purchasing food online and seeing favourite food brands advertised online were significantly associated with higher frequency of consumption of unhealthy foods and drinks after adjustment for age, sex and socio-economic status.

Conclusions: Children who have higher online engagement with food brands and content, particularly through online video, are more likely to consume unhealthy foods and drinks. Our findings highlight the need to include social media in regulations and policies designed to limit children's exposure to unhealthy food marketing. Social media companies have a greater role to play in protecting children from advertising.
\end{abstract}

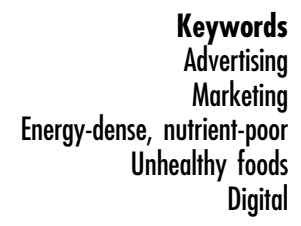

Overweight and obesity are recognised as a serious public health concern worldwide. Advertising of energy-dense, nutrient-poor (EDNP) foods and beverages is linked to overweight and obesity, thereby being a modifiable risk factor for non-communicable diseases ${ }^{(1)}$.

Marketing of EDNP foods and beverages is disproportionately targeted towards children ${ }^{(1)}$. Food promotions have been shown to influence food preferences as well as food choice and consumption behaviours in children $^{(2,3)}$. A number of studies have demonstrated a direct link between food promotion and diet-related health status, including $\mathrm{BMI}^{(1,4,5)}$.

The majority of studies on the effects of EDNP food and beverage promotions have focused on television advertising $^{(2,6)}$. Television has long dominated the advertising market share; however, in recent years, there has been an increase in digital and online media marketing in line with the rise in digital media consumption ${ }^{(6,7)}$. Children are increasingly targeted by digital media advertising of
EDNP foods and beverages, and in contrast to television, it is a largely unregulated platform ${ }^{(8)}$.

Digital advertising is becoming more sophisticated and integrated, for example through advergames and brand content on social media ${ }^{(9)}$. Such marketing strategies make it difficult for children and adolescents to differentiate between entertainment and promotional content ${ }^{(8)}$. Engagement with social media brand content includes such behaviours as reading and commenting on posts, subscribing to content such as by 'liking' brands on Facebook, and 'hashtagging' brands to link the post to other posts about the brand. Such engagement exposes children to both overt and subtle advertisements and promotions, brand messaging, competitions, offers and deals, and advergames ${ }^{(9)}$, and can contribute to children forming brand-self attachments ${ }^{(10)}$. Young people's exposure to marketing on social media has been shown to be associated with unhealthy and risky behaviours such as alcohol consumption ${ }^{(11)}$. However, little research has examined how children interact with food 
brands on social media, or how advertising and promotion on social media may affect children's food and beverage consumption $^{(12)}$. This is further complicated by the highly personalised nature of advertising content that is shown to individual social media users.

Social media use is a global phenomenon and children are particularly enthusiastic users, although most social media sites nominally prohibit those younger than 13 years of age from having an account. Ninety-two per cent of 13-17-year-olds in the USA reported going online daily in $2015^{(13)}$. Young people are avid consumers of social media, with $71 \%$ of $13-17$-year-olds in the USA using Facebook and $71 \%$ using more than one social media site $^{(13)}$. YouTube is the second-largest social networking site, after Facebook, used by $61 \%$ of Australian 8-12-yearolds and $73 \%$ of 14-17-year-olds ${ }^{(14)}$. A 2010 study found that 8-18-year-olds in the USA spent an average of $15 \mathrm{~min} / \mathrm{d}$ on video websites such as YouTube ${ }^{(15)}$.

The WHO's set of recommendations on the marketing of EDNP foods to children recommends policy aimed at reducing children's exposure to, and the power of, marketing of EDNP foods ${ }^{(16)}$. However, the lack of data about children's exposure to marketing of EDNP foods through digital media, and its effects on behaviour, makes it difficult to pursue evidence-informed policy ${ }^{(17)}$. In the present study, we aimed to examine whether online and social media behaviours in children are associated with increased consumption of EDNP foods and beverages. We hypothesised that engagement with online food brand content is associated with higher consumption of EDNP foods and beverages. This is, to our knowledge, the first study to look at the relationship between Internet and social media behaviour in children and their food and beverage consumption.

\section{Methods}

A cross-sectional online survey was conducted with 10-16-year-old children living in New South Wales, Australia, during October-November 2014. Approximately 7600 parents who were panel members of a market research company (McNair Ingenuity) were contacted by email and assessed for eligibility via a screening survey (see online supplementary material, Supplemental Fig. 1). A total of 582 parents were successfully screened and their child invited to complete the questionnaire. Sample quotas were established for age, sex and socio-economic status (based on postcode of residence using the Australian Bureau of Statistics' Socioeconomic Index for Areas) ${ }^{(18)}$ to promote an even distribution across groups. The study aimed for a target sample of 400 children and our final sample includes 417 responses. Where there were multiple eligible children per household preference was given to the oldest child, as difficulty recruiting older adolescents was anticipated. Panel members were emailed a link to the survey containing a unique identifier to monitor participation and facilitate follow-up.
The survey included an online consent form for participants to review and then click to consent to participate. Up to two reminder emails were sent and participation was rewarded with an \$AU 10 gift voucher. The study was granted ethical approval by the University of Sydney Human Research Ethics Committee.

The questionnaire (see online supplementary material, Supplemental File 1) included measures of: (i) sociodemographic characteristics, including age, sex and residential postcode as a proxy for socio-economic advantage; (ii) Internet and social media use, including engagement with social media websites, particularly Facebook and YouTube, and interactions with food and beverage brand content; and (iii) frequency of consumption of unhealthy foods and beverages.

Social media questions included frequency of checking Facebook and YouTube (from rarely or never to many times per day), if participants had ever 'liked' food and beverage companies or brands on Facebook, if they had shared food and beverage brand content on social media, and if they had ever entered a competition sponsored by a food or beverage brand on social media. Children were asked to count and name what food/beverage brands that they had 'liked' on Facebook by checking their account while completing the survey. Brands were named using an open text field.

Frequencies of food and beverage intakes were assessed using short food frequency questions, with responses ranging from more than two per day to less than one per week $^{(19)}$. These responses were dichotomised into 'less than weekly' and 'at least weekly'. This aligns with population dietary surveys ${ }^{(20)}$ and recognises that responses to short questions do not represent absolute intake but can rank low/high consumers ${ }^{(21)}$. Unhealthy food, drink and combined scores were calculated by allocating 1 point for every unhealthy item consumed at a frequency of at least weekly. The unhealthy food score comprised up to 7 points from: biscuits, cakes or muesli bars; fast food; confectionery; ice cream or ice blocks; chips and salty snacks; pre-sugared breakfast cereal; and fried potato. The unhealthy drink score comprised up to 5 points from: fruit juice; sugary drinks; flavoured milk; diet drinks; and energy drinks. The combined score was the sum of the unhealthy food and drink scores, with a maximum of 12 points.

Linear regression was used to evaluate any association between social media behaviours and food and drink scores. Both univariate analyses and multivariate analyses controlling for age, sex and socio-economic status were performed. All analyses were conducted in the statistical software package SAS Enterprise Guide 7.11.

\section{Results}

Demographic characteristics of child respondents and overall prevalence of online behaviours are shown in Table 1. 
Table 1 Characteristics and online and eating behaviours of children aged 10-16 years who responded to the online survey of social media use and eating behaviour, New South Wales, Australia, October-November 2014

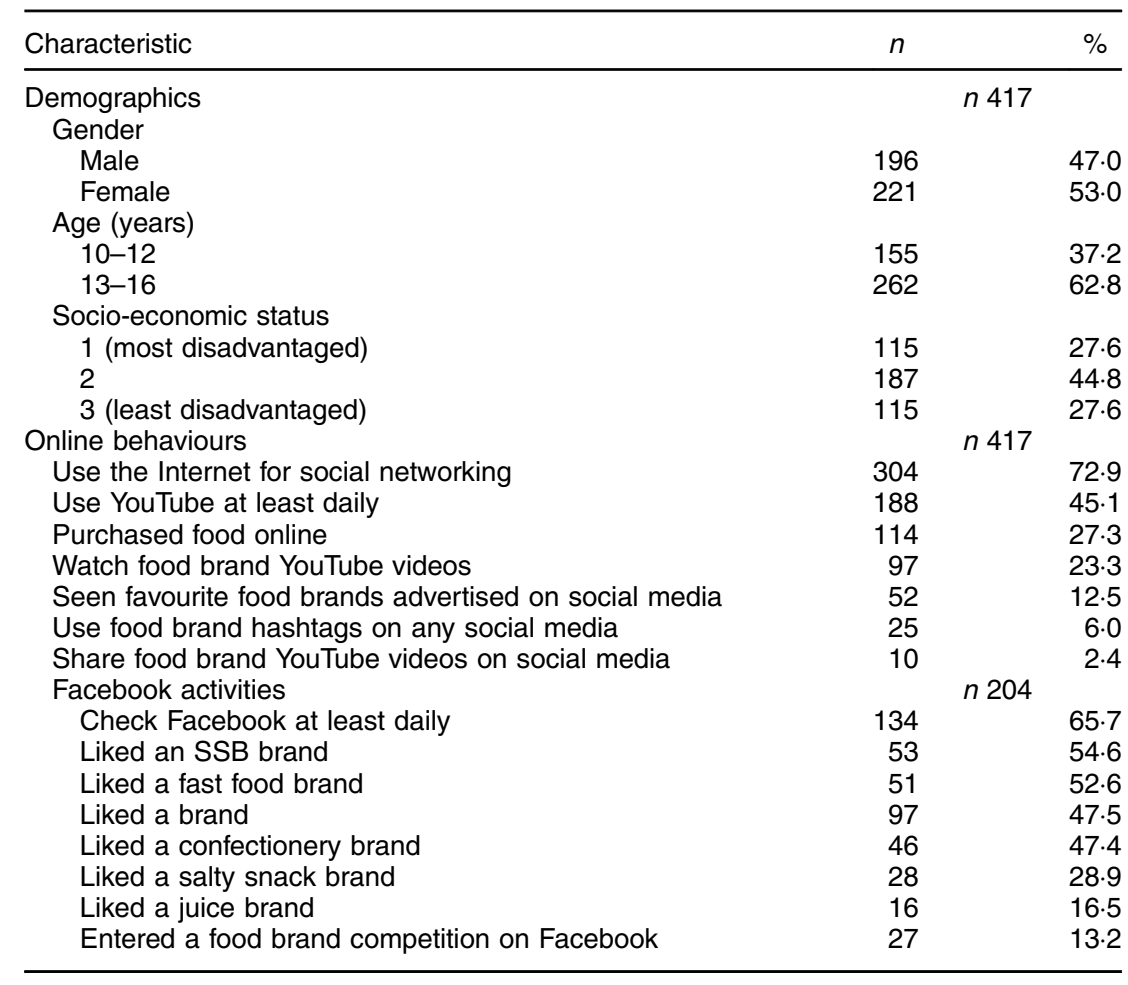

'Food brand', food or beverage brand; SSB, sugar-sweetened beverage.

Among the 417 children who responded to the survey, the most common way of accessing the Internet was on a computer at home ( $n$ 409, 98.1\%), followed by a mobile phone ( $n$ 318, 76.3\%), with 260 (63.4\%) using their own mobile phone.

\section{Social media use}

There were 304 children $(72 \cdot 9 \%)$ who said they used the Internet for social networking (Table 1), including seventy-two (46.5\%) of 10-12-year-olds and 232 (88.6\%) of 13-16-year-olds. Fifty-two children (12.5\%) reported seeing their favourite food brands advertised on social media. There were twenty-five children (6.0\%) who reported hashtagging food and beverage brands on any social media. Coke was the most frequently named hashtagged brand ( $n$ 12, $2.9 \%$ ), followed by McDonald's ( $n$ 3, $0.7 \%$ ). Over one-quarter of respondents ( $n$ 114, $27.3 \%)$ reported purchasing food online. There were 114 children $(27.3 \%$ of all respondents) who reported using the Internet to purchase food. Of those children, 103 (90.4\%) used the Internet for social media and eightythree $(72 \cdot 8 \%)$ had a Facebook account.

The majority of children watched YouTube at least a few times per week ( $n$ 329, $78.9 \%$ ), including 188 (45.1\%) who watched at least once per day. Among 10-12-yearolds, $115(72.3 \%)$ watched YouTube at least a few times per week compared with 217 (82.8\%) of 13-16-year-olds.
Ninety-seven children reported watching videos for food and drink brands on YouTube (23.3\%, Table 1), and ninety-five of those ( $97.9 \%)$ named at least one specific brand. The most frequently named brand was Coke, with thirty-three saying they had watched a Coke video (7.9\%), followed by McDonald's ( $n$ 16, 3.8\%) and Red Bull ( $n$ 12, $2 \cdot 9 \%)$. Ten children $(2 \cdot 4 \%)$ reported sharing the YouTube brand videos they watched on social media.

Almost half of respondents (48.9\%) reported having a Facebook account. Among 10-12-year-olds, nineteen $(12 \cdot 3 \%)$ had a Facebook account, compared with 185 (70.6\%) of 13-16-year-olds; the median age of children with a Facebook account was 15 (interquartile range (IQR) 14-15.5) years compared with 12 (IQR 12-13) years for children without. Of the 204 children with a Facebook account, there were ninety-seven children who had 'liked' any food or drink companies or brands on Facebook (47.5\%, Table 1). The median age of children with a Facebook account was the same as for those who had 'liked' brands compared with those who had not: 15 (IQR 14-15) years and 15 (IQR 13-16) years, respectively. The median number of brands liked on Facebook was 5 (IQR 2-10). A total of 189 food and/or beverage brands were named in the free text field, including nineteen fast food, thirty-two sugar-sweetened beverage, seventy-eight confectionery, seven salty snack and eight juice brands. There were two likes for fruit (Granny Smith apples and Bananas Australia). The most frequently named 'liked' brand was 
Coca Cola ( $n$ 47, 23.0\% of Facebook users), followed by McDonald's ( $n$ 34, 16.7\%), KFC ( $n$ 29, 14.2\%), Cadbury ( $n$ 23, 11.3\%) and Pringles ( $n$ 20, 9.8\%). Overall, fiftyseven children (29.5\%) liked at least one sugar-sweetened beverage brand, fifty-four (26.5\%) liked a fast food brand, forty-six (22.6\%) liked a confectionery brand, thirty-one (15.2\%) liked a salty snack brand and eighteen (8.8\%) liked a juice brand.

\section{Food consumption}

The mean unhealthy food score was 4.5 (SD 1.7) out of 7 , with a mean unhealthy drink score of $2 \cdot 2$ (SD 1.1) out of 5 and a mean combined score of 6.6 (SD 2.4) out of 12 . Differences in mean unhealthy scores by social media behaviours are shown in Table 2 (crude) and Table 3 (adjusted). Watching food and beverage brand videos on YouTube was significantly associated with higher unhealthy food, drink and combined scores (Tables 2 and 3). After adjustment for age, sex and socio-economic status (all of which were independently associated with the unhealthy food and drink scores), children who watched brand videos had food scores 0.46 points higher $(P=0.015)$, drink scores 0.34 points higher $(P=0.009)$ and combined scores 0.80 points higher $(P=0.003)$ on average than children who did not. There was some evidence that purchasing food online and reporting seeing favourite food and beverage brands advertised on social media were associated with higher unhealthy scores. Reporting seeing advertisements was associated with an adjusted increase of 0.63 points for the unhealthy food score $(P=0.011)$ and 0.86 points for the combined score $(P=0 \cdot 015)$, although there was no

Table 2 Crude linear regression results for social media behaviours as predictors of unhealthy consumption scores in children aged 10-16 years, New South Wales, Australia, October-November 2014

\begin{tabular}{|c|c|c|c|c|c|c|c|c|c|}
\hline \multirow[b]{2}{*}{ Characteristic } & \multicolumn{3}{|c|}{$\begin{array}{l}\text { Unhealthy food } \\
\text { score difference }\end{array}$} & \multicolumn{3}{|c|}{$\begin{array}{l}\text { Unhealthy drink } \\
\text { score difference }\end{array}$} & \multicolumn{3}{|c|}{$\begin{array}{l}\text { Unhealthy combined } \\
\text { score difference }\end{array}$} \\
\hline & $B$ & SD & $P$ value & $B$ & SD & $P$ value & $B$ & SD & $P$ value \\
\hline \multicolumn{10}{|l|}{ All respondents ( $n$ 417) } \\
\hline Purchased food online ( $n$ 114) & 0.29 & 0.18 & 0.121 & 0.24 & 0.13 & 0.054 & 0.53 & 0.26 & $0.046^{*}$ \\
\hline Watch food brand YouTube videos ( $n$ 97) & 0.42 & 0.19 & $0.030^{*}$ & 0.31 & 0.13 & $0.018^{*}$ & 0.74 & 0.28 & $0.008^{*}$ \\
\hline Seen favourite food advertised on social media ( $n$ 52) & 0.49 & 0.25 & 0.051 & 0.24 & 0.17 & 0.155 & 0.73 & 0.36 & $0.042^{*}$ \\
\hline Use YouTube at least daily ( $n 188)$ & 0.21 & 0.17 & 0.202 & 0.13 & 0.11 & 0.233 & 0.35 & 0.24 & 0.145 \\
\hline \multicolumn{10}{|l|}{ Facebook users only ( $n$ 204) } \\
\hline Liked a brand on Facebook ( $n$ 97) & 0.03 & 0.25 & 0.914 & 0.15 & 0.17 & 0.371 & 0.17 & 0.35 & 0.619 \\
\hline Entered a food brand competition ( $n$ 27) & -0.37 & 0.36 & 0.306 & -0.08 & 0.24 & 0.728 & -0.46 & 0.52 & 0.378 \\
\hline Check Facebook at least daily $(n 134)$ & -0.04 & 0.26 & 0.863 & 0.05 & 0.17 & 0.757 & 0.01 & 0.37 & 0.980 \\
\hline \multicolumn{10}{|l|}{ Demographic characteristics (all respondents; $n 417$ ) } \\
\hline \multicolumn{10}{|l|}{ Age (ref. $=10-12$ years) } \\
\hline $13-16$ years $(n 262)$ & -0.46 & 0.17 & $0.007^{*}$ & 0.08 & 0.12 & 0.496 & -0.38 & 0.24 & 0.119 \\
\hline Female ( $n$ 221) & -0.28 & 0.16 & 0.089 & -0.37 & 0.11 & $0.001^{*}$ & -0.65 & 0.24 & $0.006^{*}$ \\
\hline Socio-economic status (ref. $=2$ ) & & & $0.031^{*}$ & & & $0.006^{\star}$ & & & $0.004^{*}$ \\
\hline 1 (most disadvantaged; $n$ 115) & 0.47 & 0.20 & $0.017^{*}$ & 0.41 & 0.13 & $0.002^{*}$ & 0.89 & 0.28 & $0.002^{*}$ \\
\hline 3 (least disadvantaged; $n$ 115) & -0.03 & $0 \cdot 20$ & 0.869 & 0.05 & 0.13 & 0.716 & 0.02 & 0.28 & 0.953 \\
\hline
\end{tabular}

'Food brand', food or beverage brand; ref., reference category.

*Significant $(P<0.05)$.

Table 3 Adjusted linear regression results for social media behaviours as predictors of unhealthy consumption scores in children aged 10-16 years, New South Wales, Australia, October-November 2014

\begin{tabular}{|c|c|c|c|c|c|c|c|c|c|}
\hline \multirow[b]{2}{*}{ Characteristic } & \multicolumn{3}{|c|}{$\begin{array}{l}\text { Unhealthy food } \\
\text { score difference }\end{array}$} & \multicolumn{3}{|c|}{$\begin{array}{l}\text { Unhealthy drink } \\
\text { score difference }\end{array}$} & \multicolumn{3}{|c|}{$\begin{array}{l}\text { Unhealthy combined } \\
\text { score difference }\end{array}$} \\
\hline & $B$ & $\mathrm{SD}$ & $P$ value & $B$ & $\mathrm{SD}$ & $P$ value & $B$ & $\mathrm{SD}$ & $P$ value \\
\hline \multicolumn{10}{|l|}{ All respondents ( $n$ 417) } \\
\hline Purchased food online ( $n$ 114) & 0.45 & 0.18 & $0.015^{\star}$ & 0.26 & 0.13 & $0.037^{\star}$ & 0.71 & 0.26 & $0.009^{*}$ \\
\hline Watch food brand YouTube videos ( $n$ 97) & 0.46 & 0.19 & $0 \cdot 015^{\star}$ & 0.34 & 0.13 & $0.009^{*}$ & 0.80 & 0.27 & $0.003^{*}$ \\
\hline Seen favourite food advertised on social media ( $n 52)$ & 0.63 & 0.25 & $0.011^{*}$ & 0.23 & 0.17 & 0.166 & 0.86 & 0.35 & $0.015^{\star}$ \\
\hline Use YouTube at least daily ( $n$ 188) & 0.28 & 0.17 & 0.092 & 0.08 & 0.11 & 0.489 & 0.36 & 0.24 & 0.132 \\
\hline \multicolumn{10}{|l|}{ Facebook users only ( $n$ 204) } \\
\hline Liked a brand on Facebook ( $n$ 97) & 0.01 & 0.24 & 0.980 & 0.15 & 0.16 & 0.336 & 0.16 & 0.34 & 0.642 \\
\hline Entered a food brand competition ( $n$ 27) & -0.28 & 0.35 & 0.422 & 0.00 & 0.23 & 0.996 & -0.29 & 0.49 & 0.562 \\
\hline Check Facebook at least daily (n 134) & 0.07 & 0.26 & 0.789 & 0.15 & 0.17 & 0.364 & 0.22 & 0.36 & 0.538 \\
\hline
\end{tabular}

'Food brand', food or beverage brand.

Models are adjusted for age, sex and socio-economic status.

*Significant $(P<0.05)$. 
significant increase in the unhealthy drink score (mean difference $=0.23$ points, $P=0 \cdot 166$ ). Children who ordered food online had food scores on average 0.45 points higher $(P=0.015)$, drink scores 0.26 points higher $(P=0.037)$ and combined scores 0.71 points higher $(P=0.009)$. There were no significant associations between unhealthy scores and any of the Facebook-related or other social media behaviours examined.

\section{Discussion}

Our findings demonstrate that certain online and social media behaviours are associated with higher unhealthy food and beverage consumption. Watching brand content on YouTube and self-reported exposure to food advertising online were significantly associated with higher unhealthy food and/or beverage consumption, after adjustment for demographic factors. These findings suggest that children's exposure to advertising of EDNP foods and beverages on social media is associated with a higher consumption of those unhealthy foods and drinks. Children purchasing food online were also significantly more likely to have unhealthy consumption. This food could be purchased on behalf of the family, for example children placing the family order for pizza delivery, or for older children, ordering using their own funds, for their own consumption.

Our findings on frequency of use of Facebook and YouTube use are similar to those reported elsewhere for Australian children ${ }^{(14)}$. The fact that watching food brand videos was associated with unhealthy food consumption, while interacting with brand profiles on Facebook was not, may reflect that videos may be more engaging than other types of content. This may help explain why Facebook has increasingly shifted towards more video and image content in advertising/promoted posts. Additionally, users intentionally seek out YouTube content to view, whereas Facebook content is more passively shown to users through a scrolling newsfeed. However, the number who said they used Facebook to interact with brands was small, so the non-significant findings could also be due to the study sample size.

The association between purchasing food online and unhealthy food scores could be due to several factors. Children who place online food orders may spend more time online and be exposed to a greater number of advertisements, or be ordering unhealthy takeaway meals for themselves and their families. Online ordering may also be clustered with other unhealthy behaviours such as decreased physical activity and increased screen time.

One of the concerns about television and digital media advertising is that it makes it increasingly difficult for children to distinguish between commercial content and entertainment ${ }^{(8,22)}$. This is likely to be particularly true for uniquely integrated and interactive advertising on social media $^{(8)}$. We found that while only $12.5 \%$ reported seeing their favourite brands advertised on social media, $23 \cdot 3 \%$ of all respondents reported liking a brand on Facebook, suggesting that many children do not recognise these brand social media profiles and their content as advertising.

Study limitations include the cross-sectional design and the use of a market research panel to recruit participants. Participants may not be representative of the general population, although the recruitment strategy ensured that the sample had participants from a spread of socioeconomic backgrounds and was balanced in terms of age and gender. Further, social media platforms change their terms of service and advertising algorithms continuously, meaning that user experiences, preferences and behaviours are also subject change.

Despite the cross-sectional design, the significant associations shown between online behaviours and unhealthy consumption support calls made by public health professionals and the WHO for policy and interventions that protect children from being exposed to food and beverage brand content on digital media, as is already the case for television advertising ${ }^{(12,16,17,23)}$. There is a lack of government regulation around digital and online marketing to children internationally. Codes on food and beverage advertising to children are predominantly voluntary, and most do not include advertising on social media platforms $^{(6)}$. Our findings highlight the need to include social media in regulations and policies designed to limit children's exposure to unhealthy food marketing.

Social media sites could also adopt their own protective policies limiting the advertising of unhealthy foods and beverages to children, following similar policies implemented for tobacco advertising ${ }^{(24,25)}$, to protect their most vulnerable users. While age restrictions currently exist on some social media websites, it is clear that these are not effective. Both Facebook and YouTube are theoretically restricted to people aged 13 years or older, yet we found that $72 \%$ of $10-12$-year-olds regularly used YouTube and $12 \%$ had a Facebook account. While parental control options exist for some websites, such as the YouTube Kids app, this is aimed at younger (pre-school and early primary school) children and focuses on excluding graphic violence and sexual content. YouTube Kids does claim to prohibit any advertising of foods and beverages, regardless of nutritional content; however, complaints to the US Federal Trade Commission have suggested that food and beverage advertisements, promotional videos and product placement appear on the app ${ }^{(26)}$.

\section{Conclusions}

The interaction between advertising and food consumption is poorly studied in the context of online space, particularly with regard to children. These data provide a more complete picture of children's media consumption, offering insight into social media behaviours, how children 
interact with food brand content on social media and how this might affect unhealthy food and beverage consumption. Children who interact and engage with food brands more, particularly through online video, are more likely to consume unhealthy foods and drinks. Social media companies have a greater role to play in protecting their most vulnerable users from harmful advertising.

\section{Acknowledgements}

Acknowledgements: The authors thank Kathy Chapman and Lesley King for contributions to survey design. Financial support: Funding for this study was provided from the Australian Preventive Health Research Grants Programme. H.J.B. is supported by the NSW Biostatistics Training Programme. The funders had no role in the design, analysis or writing of this article. Conflict of interest: None. Authorship: B.F. and B.K. conceived of and designed the study, including developing the questionnaire and survey protocol. H.J.B. performed data analysis and drafted the manuscript. All authors were involved in revising the manuscript and had final approval of the submitted version. Ethics of human subject participation: This study was conducted according to the guidelines laid down in the Declaration of Helsinki and all procedures involving human subjects were approved by the University of Sydney Human Ethics Committee (protocol number 2014/540). Written informed consent was obtained from all subjects.

\section{Supplementary material}

To view supplementary material for this article, please visit https://doi.org/10.1017/S1368980018001866

\section{References}

1. Cairns G, Angus K, Hastings G et al. (2013) Systematic reviews of the evidence on the nature, extent and effects of food marketing to children. A retrospective summary. Appetite 62, 209-215.

2. Boyland EJ, Nolan S, Kelly B et al. (2016) Advertising as a cue to consume: a systematic review and meta-analysis of the effects of acute exposure to unhealthy food and nonalcoholic beverage advertising on intake in children and adults. Am J Clin Nutr 103, 519-533.

3. Kelly B, Freeman B, King L et al. (2015) Television advertising, not viewing, is associated with negative dietary patterns in children. Pediatr Obes 11, 158-160.

4. Zimmerman FJ \& Bell JF (2010) Associations of television content type and obesity in children. Am J Public Health 100, 334-340.

5. Andreyeva T, Kelly IR \& Harris JL (2011) Exposure to food advertising on television: associations with children's fast food and soft drink consumption and obesity. Econ Hum Biol 9, 221-233.

6. Dunlop S, Freeman B \& Jones SC (2016) Marketing to youth in the digital age: the promotion of unhealthy products and health promoting behaviours on social media. Media Commun 4, 35-49.

7. Harris JL, Schwartz MB, Munsell CR et al. (2013) Fast Food FACTS 2013: Measuring Progress in Nutrition and Marketing to Children and Teens. Hartford, CT: Yale Rudd Center for Food Policy \& Obesity.

8. Boelsen-Robinson T, Backholer K \& Peeters A (2015) Digital marketing of unhealthy foods to Australian children and adolescents. Health Promot Int 31, 523-533.

9. Jackson M, Harrison P, Swinburn B et al. (2014) Unhealthy food, integrated marketing communication and power: a critical analysis. Crit Public Health 24, 489-505.

10. Kelly B, Freeman B, King L et al. (2016) The normative power of food promotions: Australian children's attachments to unhealthy food brands. Public Health Nutr 19, 2940-2948.

11. Hoffman EW, Pinkleton BE, Weintraub Austin E et al. (2014) Exploring college students' use of general and alcoholrelated social media and their associations with alcoholrelated behaviors. J Am Coll Health 62, 328-335.

12. Freeman B, Kelly B, Baur L et al. (2014) Digital junk: food and beverage marketing on Facebook. Am J Public Health 104, e56-e64.

13. Pew Research Center (2015) Teen, Social Media and Technology Overview 2015. Washington, DC: Pew Research Center.

14. Australian Communications and Media Authority (2011) Like, Post, Share: Young Australians' Experience of Social Media. Canberra: Australian Communications and Media Authority.

15. Rideout VJ, Foher UG \& Roberts DF (2010) Generation M2: Media in the Lives of 8-18-Year-Olds. Menlo Park, CA: Kaiser Family Foundation.

16. World Health Organization (2010) Set of Recommendations on the Marketing of Foods and Non-Alcoholic Beverages to Children. Geneva: WHO.

17. World Health Organization (2016) Tackling Food Marketing to Children in a Digital World: Trans-Disciplinary Perspectives. Children's Rights, Evidence of Impact, Methodological Challenges, Regulatory Options and Policy Implications for the WHO European Region. Geneva: WHO.

18. Australian Bureau of Statistics (2011) Census of Population and Housing: Socio-Economic Indexes for Areas (SEIFA). http://www.abs.gov.au/ausstats/abs@.nsf/mf/2033.0.55.001 (accessed September 2017).

19. Hardy LL, King L, Espinel P et al. (2011) NSW Schools Physical Activity and Nutrition Survey (SPANS) 2010: Full Report. Sydney: NSW Ministry of Health.

20. Hardy LL, King L, Espinel P et al. (2011) NSW Schools Physical Activity and Nutrition Survey (SPANS) 2010: Short Report. Sydney: NSW Ministry of Health.

21. Riley M, Rutishauser I \& Webb K (2001) Comparison of Short Questions with Weighed Dietary Records. Canberra: Commonwealth Department of Health and Aged Care.

22. Moore ES \& Rideout VJ (2007) The online marketing of food to children: is it just fun and games? J Public Policy Mark 26, 202-220.

23. Freeman B, Kelly B, Vandevijvere S et al. (2015) Young adults: beloved by food and drink marketers and forgotten by public health? Health Promot Int 31, 954-961.

24. Facebook Inc. (2017) Advertising Policies. https://www. facebook.com/policies/ads (accessed September 2017).

25. Google Inc. (2017) Dangerous products or services. https:// www.support.google.com/adwordspolicy/answer/6014299 ?hl=en (accessed September 2017).

26. Greenberg J (2015) YouTube's Kids app is coming under fire for junk food ads. Wired. https://www.wired.com/2015/ 11/youtubes-kids-app-is-coming-under-fire-for-junk-food-ads/ (accessed September 2017). 